\title{
Determination of Total Concentrations and Chemical and Physical Fractionation Forms of Manganese in Infusions of Ground Coffees
}

\author{
Pawel Pohl • Ewelina Stelmach • Anna Szymczycha-Madeja
}

Received: 30 April 2013 / Accepted: 1 July 2013 / Published online: 23 July 2013

(C) The Author(s) 2013. This article is published with open access at Springerlink.com

\begin{abstract}
A simple and fast method of the determination of total $\mathrm{Mn}$ in infusions of ground coffees was proposed and included the acidification of infusions with $\mathrm{HNO}_{3}$ followed by the analysis by flame atomic absorption spectrometry. The method provided the precision and the accuracy better than $3 \%$. In addition, chemical and physical fractionation patterns of Mn in coffee infusions were assessed using solid phase extraction and ultrafiltration-based procedures, respectively. It was found that $\mathrm{Mn}$ in infusions of ground coffees is predominantly present in the form of cationic (64-81\% of the total content) low molecular weight (61$68 \%$ of the total content) species. This points out that this metal is highly bioaccessible from the coffee brew.
\end{abstract}

Keywords Coffee $\cdot \mathrm{Mn} \cdot$ Fractionation $\cdot$ Solid phase extraction · Ultrafiltration · Flame atomic absorption spectrometry

\section{Introduction}

Commercial and social importance of coffee is obvious and therefore great awareness and concern to the elemental composition of this beverage is attached (Pohl et al. 2013). The information on the total concentration of minerals, micronutrients, or trace elements in coffee is commonly used to assess its quality and safety or differentiate types of this beverage (Dos Santos et al. 2010; Bertrand et al. 2008; Filho et al. 2007; Grembecka et al. 2007; Fernandes et al. 2005; Dos Santos and de Oliveira 2001; Martin et al. 1996, 1999; Onianwa et al. 1999). On the other hand, the total content analysis is considered to judge the

P. Pohl $(\bowtie) \cdot$ E. Stelmach $\cdot$ A. Szymczycha-Madeja Department of Analytical Chemistry, Faculty of Chemistry,

Wroclaw University of Technology, Wybrzeze Stanislawa

Wyspianskiego 27, 50-370 Wroclaw, Poland

e-mail: pawel.pohl@pwr.wroc.pl nutritional value of coffee and evaluate the degree of the coverage of daily dietary intakes of various elements through a customary drinking of coffee brews (Ashu and Chandravanshi 2011; Filho et al. 2007; Grembecka et al. 2007; Santos et al. 2004; Suseela et al. 2001). In the latter case, such a treatment is not entirely justified and cannot be either decisive when considering the uptake of elements from coffee or its role in the human nutrition.

The actual bioavailability of elements is primarily associated with properties of speciation forms in which they are present (Templeton et al. 2000). Major, minor, and trace elements, especially metals, could exist in coffee infusions in the form of simple ions and complexing ions of different stability with various (low, moderate, and high molecular weight) endogenous bioligands, e.g., phenolic acids and flavonoids as reported for instance for tea infusions (Matsuura et al. 2001; Erdemoglu et al. 2000; Powell et al. 1998; Odegard and Lund 1997). The presence of various species of metals can affect the yield of their transfer from coffee powders into infusions during the brewing since ultimate physicochemical forms of elements have different solubilities (Jaganyi et al. 1999).

Indisputably, the knowledge about the type of speciation forms of metals bound to various endogenous bioligands in coffee and the distribution elements' species having different functionalities appears to be critically important to predict their bioavailability from this beverage and the degree of the absorption through the gastrointestinal tract as reported for other food and beverages (Schumann and Elsenhans 2002; Powell et al. 1998; Watzke 1998; Cairns et al. 1996). Surprisingly, this problem related to coffee is not firmly established in the literature and therefore, it scarifies for a special attention and a research activity. In this respect, the identification and the quantification of ultimate physicochemical forms of various metals in coffee infusions are extremely important for the evaluation of their actual bioavailability and eventual health and nutrition benefits of coffee. The direct determination of specific forms of metals 
can be difficult due to a great number of their individual species and the lack of appropriate standards for the identification of such species. It can be assumed that the relevant information in regard to possible speciation forms of metals released into coffee infusions during the brewing could be provided when operational aspects of the speciation analysis would be considered and the fractionation approach would be used as previously reported in case of tea (Erdemoglu et al. 2000; Ozdemir and Gucer 1998; Odegard and Lund 1997), milk (Pohl and Prusisz 2007; Abollino et al. 1998), beer (Pohl 2007; Svendsen and Lund 2000) and wine (Karadjova et al. 2002; McKinnon and Scollary 1997). Such an approach would enable to determine groups or classes of species of metals differing due to chemical and/or physical properties and the data achieved would be more convenient and instructive for the interpretation (Gonzalvez et al. 2009).

The aim of the present contribution was (1) to develop the method of the direct analysis of coffee infusions on the total concentration of $\mathrm{Mn}$ in infusions of ground coffees and its application for coffees available in the Polish market and (2) to assess the partitioning profile of $\mathrm{Mn}$ in coffee infusions through the chemical and the physical fractionation in order to provide the information on the possible bioaccessibility of this metal form the coffee brew. Manganese was selected for the study since it is the metal reported to be the best suited for the identification of the origin of coffee and coffee infusions and extremely important for enzymatic processes in living organisms (Grembecka et al. 2007; Oleszczuk et al. 2007; Anderson and Smith 2002).

\section{Materials and Methods}

\section{Reagents and Samples}

Solutions of ACS grade $30 \%(\mathrm{~m} / \mathrm{m}) \mathrm{H}_{2} \mathrm{O}_{2}, 37 \%(\mathrm{~m} / \mathrm{m}) \mathrm{HCl}$ and $65 \%(\mathrm{~m} / \mathrm{m}) \mathrm{HNO}_{3}$ were purchased from J. T. Baker (Deventer, Netherlands). A TraceCERT ${ }^{\circledR}$ single-element $1,000 \mathrm{mg} \mathrm{L}^{-1}$ standard of Mn was supplied by SigmaAldrich Chemie GmbH (Steinheim, Germany). This solution was used to prepare standard solutions for the calibration. Redistilled water was used in all preparations.

Eight roasted and ground coffees, widely present in the Polish market, were chosen for the analysis. The selection included the following brands: Maxwell House (MH), Café Prima Finezja (CPF), Woseba Rodzinna (WR), Tchibo Family (TF), Tchibo Espresso (TE), Jacobs Aroma (JA), Jacobs Kronung (JK), and Jacobs Cronat Gold (JCG).

\section{Instrumentation}

Measurements of Mn concentrations in all coffee digests and infusions as well as effluents, eluates, filtrates, and permeates were made by flame atomic absorption spectrometer (FAAS) using a Perkin Elmer (Waltham, MA, USA) single-beam spectrometer model 1100B. The instrument was equipped with a single-slot $10-\mathrm{cm}$ burner head and a premix burner chamber with an end cup and a drain interlock assemblage. A stainless steel nebulizer was used to aspirate sample and standard solutions, while a flow spoiler was applied to discriminate the size of droplets in the solution aerosol formed. Instrumental settings recommended by the instrument manufacturer were applied in case of measurements of $\mathrm{Mn}$ in a very sharp air-acetylene-lean flame, i.e., the flow rate of acetylene, $1.4 \mathrm{~L} \mathrm{~min}^{-1}$; the flow rate of air, $8.0 \mathrm{~L} \mathrm{~min}^{-1}$; the wavelength, $279.5 \mathrm{~nm}$; the width slit, $0.2 \mathrm{~nm}$; and the HCL lump current, $30 \mathrm{~mA}$. Absorbance readings were carried out using a time-average integration mode. In each read cycle, three readings were integrated at 0.1 -s intervals over a 3-s integration time and averaged. Five standard solutions in the concentration range from 0.05 to $1.00 \mathrm{mg} \mathrm{L}^{-1}$ were used. The instrumental detection limit was $0.007 \mathrm{mg} \mathrm{L}^{-1}$, while the reproducibility of consecutive measurements of standard solutions of $\mathrm{Mn}$ at different concentrations was within $0.6-$ $3.8 \%$ (as the relative standard deviation, RSD).

\section{Preparation and Analysis of Coffee Infusions}

Coffee infusions were prepared as follows: 6.0 -g portions of analyzed coffees were placed in $400 \mathrm{ml}$ Pyrex glass beakers and poured with $200 \mathrm{~mL}$ of boiled water. After $10 \mathrm{~min}$, resulting infusions were separated from grounds by filtrating them through precleaned dense cellulose filter papers.

Concentrations of $\mathrm{Mn}$ in coffee infusions were determined as follows: $10-\mathrm{mL}$ portions of infusions were sampled and placed in 14-mL round bottom polypropylene tubes. Then, they were acidified with $1.0 \mathrm{ml}$ of a concentrated $\mathrm{HNO}_{3}$ solution and next, directly analyzed by FAAS against simple standard solutions. In addition, similar portions of coffee infusions were open vessel digested. Accordingly, 10$\mathrm{mL}$ portions of infusions were placed in 50-mL Pyrex glass beakers and evaporated under the cover nearly to the dryness on a hot plate. Liquid residues left were treated with $2.0 \mathrm{~mL}$ of a concentrated $\mathrm{HNO}_{3}$ solution, heated under the cover to decompose them, and evaporated to reduce the volume to about $1 \mathrm{~mL}$. Finally, resulting aliquots were diluted with water to $10 \mathrm{~mL}$. These solutions were analyzed by FAAS on the content of $\mathrm{Mn}$ against simple standard solutions and using the method of two standard additions.

The open vessel wet digestion of analyzed ground coffees was as follows: 1.0 -g coffee samples were placed in $150-\mathrm{mL}$ Pyrex glass beakers, $10 \mathrm{~mL}$ of a concentrated $\mathrm{HNO}_{3}$ solution were added to them and left overnight for the predigestion. Then, samples were hot-plate digested under the cover. When the volume of resulting sample solutions was decreased to about $2 \mathrm{~mL}, 10 \mathrm{~mL}$ of a concentrated $\mathrm{H}_{2} \mathrm{O}_{2}$ 
solution were added. The heating was continued to evaporate these solutions almost to the dryness. Liquid residues left were quantitatively transferred to $25-\mathrm{mL}$ Pyrex calibrated flasks and diluted to the volume with water. These solutions were analyzed by FAAS versus simple standard solutions.

All sample solutions were prepared in triplicate. Concentrations of Mn were measured in undiluted sample solutions. Respective procedural blanks were prepared and considered in final results.

\section{Chemical Fractionation Procedure}

The chemical fractionation of Mn was carried out using a twocolumn SPE procedure (see Fig. 1). Two types of SigmaAldrich SPE tubes were used, i.e., Discovery DSC-18 and Discovery DSC-SCX, containing polymerically bounded octadecyl and benzenosulfonic groups, respectively. SPE tubes were filled with $500 \mathrm{mg}$ of sorbents having the particle size of $50 \mu \mathrm{m}$. Before using, both SPE tubes were preconditioned. In case of DSC-18 tubes, sorbent beds were washed with $5.0 \mathrm{~mL}$ of methanol and next with $10 \mathrm{~mL}$ of water. Sorbent beds of DSC-SCX tubes were washed with $5.0 \mathrm{~mL}$ of $2.0 \mathrm{~mol} \mathrm{~L}^{-1} \mathrm{HCl}$ solution and next with $10 \mathrm{~mL}$ of water.

Prior to the partitioning of Mn species in untreated infusions of analyzed coffees, their 20 -mL portions were passed at a flow rate of $2.0 \mathrm{~mL} \mathrm{~min}^{-1}$ through DSC-18 SPE tubes to retain hydrophobic species of Mn. Resulting effluents were saved and used for further analysis. Accordingly, the concentration of Mn species not retained by DSC-18 tubes was determined in 5.0-mL portions of these effluents to evaluate the concentration of hydrophobic species of the metal and the contribution of its hydrophobic fraction (HF). The rest of the part of the mentioned effluents were passed at a flow rate of $2.0 \mathrm{~mL} \mathrm{~min}{ }^{-1}$ through DSC-SCX SPE tubes to retain cationic species of Mn. Resulting effluents were subjected to the analysis on the content of $\mathrm{Mn}$ species not retained by both types of SPE tubes, i.e., the residual fraction (RF) of this metal. Finally, cationic species of Mn retained by DSC-SCX SPE tubes were eluted using $5.0 \mathrm{~mL}$ of a $2.0 \mathrm{~mol} \mathrm{~L}^{-1} \mathrm{HCl}$ solution and the concentration of $\mathrm{Mn}$ in collected eluates was determined to evaluate the contribution of the cationic fraction $(\mathrm{CF})$ of this metal. For each coffee, the procedure was undertaken in triplicate using fresh infusion portions. Effluents were analyzed by FAAS after their previous acidification with $\mathrm{HNO}_{3}$ (at $1.3 \mathrm{~mol} \mathrm{~L}^{-1}$ ). Eluates were directly analyzed by FAAS. In both cases, concentrations of Mn were determined against simple standard solutions and respective procedural blanks.

\section{Physical Fractionation Procedure}

A Millipore (Billerica, MA, USA) 8200 UF stirred cell with a stirring bar and a 200-mL sample reservoir were used for the physical fractionation of Mn through the ultrafiltration. Pressure in the cell was sustained with compressed $\mathrm{N}_{2}$ and adjusted during the ultrafiltration from 25 to 50 psi. At first, $200 \mathrm{~mL}$ of infusions of analyzed coffees were filtrated through $0.45 \mu \mathrm{m}$ filters (Nylone 66 membrane filters, Sigma-Aldrich). Then, 20-mL portions of filtered coffee brews were placed in a cell reservoir and passed through a Millipore Biomax PB polyethersulfone membrane of a given molecular weight cutoff (MWCO), i.e., 5, 10, 30, 50, and $100 \mathrm{kDa}$. Respective permeates were collected and their 5.0$\mathrm{mL}$ portions were analyzed by FAAS after the previous
Fig. 1 Schemes of chemical and physical fractionation of $\mathrm{Mn}$ in coffee infusions

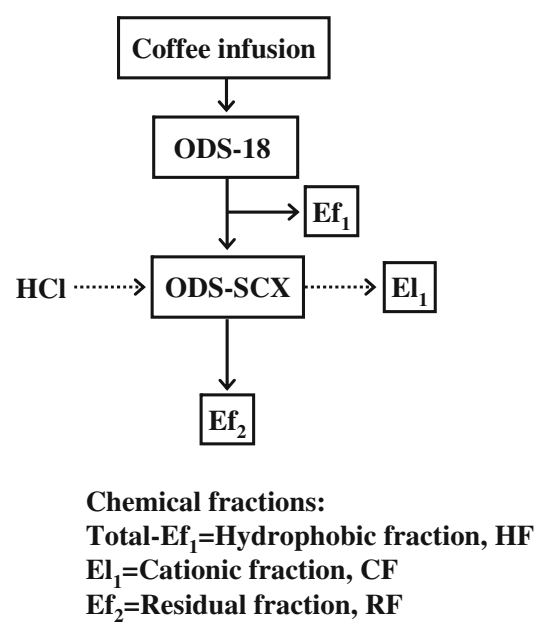

Loading $(\longrightarrow$ and elution (….)

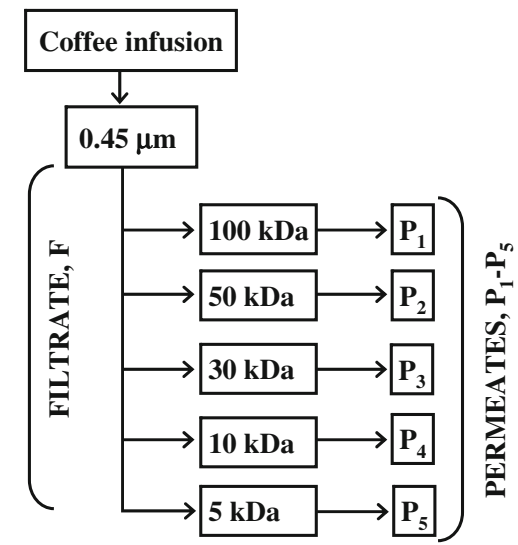

Physical fractions:

$P_{5}=<5 \mathrm{kDa}$

$P_{4}-P_{5}=5-10 \mathrm{kDa}$

$\mathbf{P}_{3}-\mathbf{P}_{4}=10-30 \mathrm{kDa}$

$\mathrm{P}_{2}-\mathrm{P}_{3}=30-50 \mathrm{kDa}$

$P_{1}-P_{2}=50-100 \mathrm{kDa}$

$\mathrm{F}-\mathrm{P}_{1}=>100 \mathrm{kDa}$ 
acidification with $\mathrm{HNO}_{3}$ at the concentration of $1.3 \mathrm{~mol} \mathrm{~L}^{-1}$. Concentrations of $\mathrm{Mn}$ in fractions of species having the MWCO lower than 5, 10, 30, 50, and $100 \mathrm{kDa}$, respectively, were determined against simple standard solutions and respective procedural blanks. The analysis was performed for selected coffees only, i.e., TF, TE, JA, JK, and JCG, and was carried out in two replicates. Contributions of the following physical fractions were calculated $>100,50-100,30-50,10$ $30,5-10$, and $<5 \mathrm{kDa}$ (see Fig. 1).

\section{Results and Discussion}

Suitability of Different Pretreatments of Coffee Infusions

In general, the elemental analysis of ground coffee infusions is rare (Pohl et al. 2013). In case of FAAS measurements, portions of infusions are commonly evaporated to the near dryness, while remaining residues are ashed and reconstituted in a $\mathrm{HCl}$ solution (Grembecka et al. 2007) or digested in a mixture of concentrated $\mathrm{HNO}_{3}$ and $\mathrm{HClO}_{4}$ solutions (Ashu and Chandravanshi 2011). When inductively coupled plasma optical emission spectrometry is used, it was reported that infusions might be directly analyzed without any pretreatment (Jaganyi and Madlala 2000) or after the previous acidification with $\mathrm{HNO}_{3}$ only (Fernandes et al. 2005). No such method has been reported so far for FAAS. Hence, in the present work, the suitability of the direct method of the analysis of ground coffee infusions by FAAS was verified, including different sample treatments, i.e., the direct analysis with and without the acidification with $\mathrm{HNO}_{3}$ or after the addition of $\mathrm{H}_{2} \mathrm{O}_{2}$.

Results of the FAAS analysis of infusions of three selected ground coffees (MH, CPF, and WR) pretreated in different ways are given in Table 1. A paired $t$ test $(\alpha=0.05)$ was used to compare concentrations of Mn determined by FAAS in all coffee infusions pretreated before measurements using alternative sample preparation methods and the calibration with simple standard solutions with those resulted from the open vessel digestion with the calibration by two standard additions, selected as the reference method. As can be seen, the best results were achieved when coffee infusions were previously acidified with $\mathrm{HNO}_{3}$ at low concentrations, i.e., 0.7 and $1.3 \mathrm{~mol} \mathrm{~L}^{-1}$. The direct analysis of untreated coffee infusions was also valid. All three methods of the analysis gave results that did not differ from those obtained using the reference method of the analysis (see calculated values of the paired $t$ test). The acidification of infusions with $\mathrm{HNO}_{3}$ to a higher concentration or the addition of $\mathrm{H}_{2} \mathrm{O}_{2}$ were found to produce systematically higher and lower results $\left(|t|>t_{\text {critical }}\right)$, respectively, as compared to results obtained with the reference method.

To avoid memory effects in the sample introduction system of the spectrometer, the procedure of the previous acidification of coffee infusions with $\mathrm{HNO}_{3}$ to the final concentration of $1.3 \mathrm{~mol} \mathrm{~L}^{-1}$ was selected for further experiments. In this case, the precision of replicated measurements was established to be within $1.4-2.4 \%$ (as the RSD). The accuracy of this method was assessed by adding simple Mn(II) ions to analyzed coffee infusions at concentrations of $0.1,0.2$, and $0.3 \mathrm{mg} \mathrm{L}^{-1}$ and performing the recovery test. The relative standard error (RSE) of recoveries of $\mathrm{Mn}$ from analyzed coffee infusions was found to vary from -1.8 to $2.6 \%$. Both measures, i.e., the precision and the accuracy, confirm that the proposed method of the sample pretreatment and the analysis of coffee infusions is reliable and quite convenient for the fast determination of the total content of $\mathrm{Mn}$ in coffee infusions. This simplified sample preparation procedure was applied at latter stages of the present work.

Total Concentrations of $\mathrm{Mn}$ in Coffee and Coffee Infusions

Total concentrations of $\mathrm{Mn}$ were determined in infusions of other five coffees available in Poland (see results in Table 2). As can be seen, the concentration of $\mathrm{Mn}$ in infusions of analyzed coffees changes from 0.19 to $0.44 \mathrm{mg} \mathrm{L}^{-1}$ with the average value of $0.30 \mathrm{mg} \mathrm{L}^{-1}$ and the coefficient of variance (CV) of $28.8 \%$. These results are well situated within concentration ranges specified by Ashu and Chandravanshi (2011) and Santos et al. (2004) for infusions of coffees originated from Ethiopia and Brazil, i.e., $0.19-0.43 \mathrm{mg} \mathrm{L}^{-1}$. Additionally, samples of analyzed ground coffees were digested while resulting sample solutions were measured by FAAS against simple standard solutions. This enabled to evaluate the content of $\mathrm{Mn}$ in the solid material and the percentage of the release of this metal during the infusing process. Results on total concentrations of $\mathrm{Mn}$ in analyzed coffees and percentages of $\mathrm{Mn}$ released from coffee powders into their infusions are given in Table 2 as well. Total concentrations of $\mathrm{Mn}$ in analyzed ground coffees were established to be close to each other; the average concentration of Mn was $22.6 \mu \mathrm{g} \mathrm{g}^{-1}(2.26 \mathrm{mg}$ of $\mathrm{Mn}$ in $100 \mathrm{~g}$ of coffee as received) with the CV of $18.5 \%$. These results are in a very good agreement with those reported by other authors (Ashu and Chandravanshi 2011; Grembecka et al. 2007), who found that the concentration of $\mathrm{Mn}$ in ground coffees is rather concise and changes in the range from 16.5 to $46.6 \mu \mathrm{g} \mathrm{g}^{-1}$. The same authors reported that the percentage of Mn leached into coffee infusions could be however quite differentiated, i.e., from 8.8 to $51.5 \%$. In the present work, the percentage of Mn leached into infusions of analyzed coffees was established to be within $33.2-56.2 \%$ and could be high due to a long brewing time used, i.e., $10 \mathrm{~min}$.

\section{Chemical Fractionation Analysis}

The chemical fractionation procedure proposed in the present study was based on the sequential SPE with extraction tubes retaining Mn species via hydrophobic (DSC-18) and 
Table 1 Total concentrations of Mn determined in coffee infusions prepared using different sample pretreatments: the open vessel wet digestion with two standard additions (A) and external standards (B); the acidification with $\mathrm{HNO}_{3}$ to the concentrations of $0.7 \mathrm{~mol} \mathrm{~L}{ }^{-1}(\mathrm{C})$, $1.3 \mathrm{~mol} \mathrm{~L}^{-1}$ (D), and $2.3 \mathrm{~mol} \mathrm{~L}^{-1}(\mathrm{E})$; the addition of $\mathrm{H}_{2} \mathrm{O}_{2}$ to the concentration $2.7 \%(\mathrm{~m} / \mathrm{v})(\mathrm{F})$; and no pretreatment $(\mathrm{G})$

\begin{tabular}{lllll}
\hline Sample pre-treatment & MH & CPF & WR \\
\hline A & $0.130 \pm 0.003$ & $0.285 \pm 0.008$ & $0.256 \pm 0.008$ & - \\
B & $0.128 \pm 0.004$ & $0.288 \pm 0.009$ & $0.252 \pm 0.007$ & -0.480 \\
C & $0.125 \pm 0.002$ & $0.287 \pm 0.004$ & $0.254 \pm 0.004$ & -0.822 \\
D & $0.127 \pm 0.003$ & $0.285 \pm 0.005$ & $0.255 \pm 0.006$ & -1.512 \\
E & $0.132 \pm 0.003$ & $0.289 \pm 0.008$ & $0.260 \pm 0.007$ & +5.000 \\
F & $0.127 \pm 0.003$ & $0.281 \pm 0.006$ & $0.250 \pm 0.005$ & -4.914 \\
G & $0.125 \pm 0.003$ & $0.286 \pm 0.004$ & $0.261 \pm 0.005$ & +0.115 \\
\hline
\end{tabular}

Average values $(n=5) \pm \mathrm{SDs}$

$t_{\text {critical }}(\alpha=0.05)$ for the $t$ paired test, 4.300

electrostatic (DSC-SCX) interactions. This enabled to distinguish three operationally defined fractions of this metal, i.e., the HF likely attributing to the presence of species of $\mathrm{Mn}$ bound to high and moderate molecular weight hydrophobic compounds such as polyphenols (Esquivel and Jimenez 2012; Hecimovic et al. 2011), the CF including simple $\mathrm{Mn}(\mathrm{II})$ ions, its stable catonic complexes with low molecular weight ligands, i.e., organic acids (Rodrigues et al. 2007) and low molecular weight Maillard reaction products (Liu and Kitts 2011), and labile species of this metal, and finally the RF possibly referred to the presence of any anion and/or neutral hydrophilic complexes of Mn.

At the outset, sorption properties of DSC-18 SPE tubes toward simple ions of $\mathrm{Mn}$ (II) and its complexes formed in the presence of citric acid (at $400 \mathrm{mg} \mathrm{L}^{-1}$ ) were verified at the $\mathrm{pH}$ of 4.0, 4.5, 5.0, and 5.5 to assure that the contribution of the HF of Mn would not be overestimated by ionic species of this metal. Analyzing effluents of these SPE tubes, it was established that both kinds of ionic species of Mn were not retained by DSC-18 SPE tubes. Accordingly, in case of working solutions containing simple $\mathrm{Mn}$ (II) ions at the concentration of $0.2 \mathrm{mg} \mathrm{L}^{-1}$ and the $\mathrm{pH}$ of solutions within the range of 4.0-5.5, Mn was recovered from effluents collected with efficiencies ranged from 99.6 to $100.8 \%$. In case of working solutions containing $\mathrm{Mn}$ (II) ions and citric acid, related recoveries of this metal were also found to be quantitative (99.3-99.9\%) for the whole studied $\mathrm{pH}$ range.

DSC-SCX SPE tubes were found to completely retain Mn from solutions containing simple $\mathrm{Mn}$ (II) ions at the $\mathrm{pH} 4.0$ 5.5. In this case, the quantitative recovery of this metal was achieved using $5.0 \mathrm{~mL}$ of a $2.0 \mathrm{~mol} \mathrm{~L}^{-1} \mathrm{HCl}$ solution. The same effect, i.e., recoveries ranged from 99.0 to $100.3 \%$,

Table 2 Total concentrations of Mn in ground coffees and their infusions in addition to contributions of chemical fractions distinguished using solid phase extraction procedure

\begin{tabular}{|c|c|c|c|c|c|c|c|}
\hline MH & $\mathrm{CPF}$ & WR & $\mathrm{TF}$ & $\mathrm{TE}$ & JA & $\mathrm{JK}$ & JCG \\
\hline \multicolumn{8}{|c|}{ Total concentration (in $\mu \mathrm{g} \mathrm{g}^{-1}$ of dry weight) in ground coffee } \\
\hline $17.3 \pm 0.4$ & $22.1 \pm 0.4$ & $19.7 \pm 0.2$ & $19.4 \pm 0.2$ & $30.0 \pm 0.3$ & $26.6 \pm 0.4$ & $24.4 \pm 0.3$ & $21.5 \pm 0.2$ \\
\hline \multicolumn{8}{|c|}{ Total concentration (in $\mu \mathrm{g} \mathrm{mL}^{-1}$ ) in ground coffee infusion } \\
\hline $0.226 \pm 0.005$ & $0.285 \pm 0.006$ & $0.252 \pm 0.005$ & $0.193 \pm 0.005$ & $0.443 \pm 0.004$ & $0.277 \pm 0.006$ & $0.407 \pm 0.010$ & $0.325 \pm 0.007$ \\
\hline \multicolumn{8}{|c|}{ Percentage of metal released from ground coffee into coffee infusion } \\
\hline 43.5 & 43.0 & 42.6 & 33.2 & 49.2 & 34.7 & 56.2 & 49.3 \\
\hline \multicolumn{8}{|c|}{ Contribution (in \%) of hydrophobic fraction (HF) } \\
\hline $10.9 \pm 2.7$ & $12.0 \pm 0.9$ & $16.3 \pm 2.1$ & $6.5 \pm 2.7$ & $18.1 \pm 1.2$ & $14.2 \pm 2.1$ & $6.7 \pm 0.4$ & $9.3 \pm 4.4$ \\
\hline \multicolumn{8}{|c|}{ Contribution (in \%) of cationic fraction (CF) } \\
\hline $75.6 \pm 3.5$ & $72.8 \pm 1.1$ & $69.2 \pm 1.8$ & $79.0 \pm 0.4$ & $74.1 \pm 1.2$ & $64.5 \pm 1.2$ & $80.9 \pm 1.8$ & $77.3 \pm 0.9$ \\
\hline \multicolumn{8}{|c|}{ Contribution (in \%) of residual fraction (RF) } \\
\hline $12.2 \pm 0.3$ & $15.9 \pm 2.0$ & $13.6 \pm 2.5$ & $14.1 \pm 7.7$ & $6.4 \pm 1.7$ & $22.2 \pm 5.5$ & $10.9 \pm 0.1$ & $11.5 \pm 0.1$ \\
\hline \multicolumn{8}{|c|}{ Sum of fractions (in \%) } \\
\hline $98.7 \pm 4.4$ & $100.7 \pm 2.4$ & $99.1 \pm 3.7$ & $99.6 \pm 8.2$ & $98.6 \pm 2.4$ & $100.9 \pm 6.0$ & $98.5 \pm 1.8$ & $98.1 \pm 4.5$ \\
\hline
\end{tabular}

Average values $(n=3) \pm$ SDs 
was also produced when $5.0 \mathrm{~mL}$ of 1.0 and $4.0 \mathrm{~mol} \mathrm{~L}^{-1} \mathrm{HCl}$ solutions were used for the elution. However, in case of the latter eluent, the determination of Mn by FAAS was made against matrix-matched standard solutions. DSC-SCX tubes were also found to retain $\mathrm{Mn}$ from working solutions containing simple $\mathrm{Mn}(\mathrm{II})$ ions and citric acid within the $\mathrm{pH}$ of 4.0-5.5, likely due to the formation of $\mathrm{MnHCit}^{+}$complexing ions, i.e., $87.3 \pm 1.6 \%(\mathrm{pH} 4.0), 72.9 \pm 2.0 \%(\mathrm{pH} 4.5)$, $45.4 \pm 0.7 \%(\mathrm{pH} 5.0)$, and $17.7 \pm 0.3 \%$ (pH 5.5).

Contributions of chemical fractions of Mn distinguished using the SPE procedure are given in Table 2. Sums of contributions of these fractions are additionally given and, as can be seen, differences between sums of concentrations of $\mathrm{Mn}$ in separated fractions and total concentrations of this metal in infusions of analyzed coffees are changed from -1.9 to $+0.7 \%$ (as RSE), what proves the validity of this partitioning procedure. In reference to total concentrations of Mn determined in infusions of all analyzed coffees, it was established that the $\mathrm{CF}$ is the predominant group of $\mathrm{Mn}$ species present in coffee brews. The donation of this fraction was found to be within $64-81 \%$ with the average abundance of $74.2 \%$ and the $\mathrm{CV}$ of $7.2 \%$. Contributions of the HF and the RF of Mn were established to be corresponding to each other. Accordingly, the concentration of $\mathrm{Mn}$ in the first group of species was found to change from 7 to $18 \%$ of its total content (with the average of $11.8 \%$ and the $\mathrm{CV}$ of $36.2 \%$ ), while the concentration of residual species of Mn was from 6 to $22 \%$ of its total content (with the average of $13.4 \%$ and the CV of $34.0 \%$ ). All this points out that $\mathrm{Mn}$ in coffee infusions has rather a cationic character; however, the affinity of this metal to form complexes with high and moderate molecular weight hydrophobic compounds of the coffee matrix and the release of such soluble species should not be neglected. A relatively high donation of the $\mathrm{CF}$ of $\mathrm{Mn}$ in coffee infusions tends to the conclusion that species of this metal can be highly soluble during the ingestion and easily taken in by the body, similarly as was reported for Mn in tea infusions by Powell et al. (1998). In view of this, it can be assumed that almost $75 \%$ of total Mn may be bioaccessible from coffee brews uptake.

\section{Physical Fractionation Analysis}

To provide comprehensive information about the physical speciation of $\mathrm{Mn}$ in reference to molecular weight of its species present in infusions of analyzed coffees, the physical fractionation by the ultrafiltration was used. To avoid an inconvenience of the sequential ultrafiltration related to a relatively high volume of the infusion analyzed at once and a possible fouling of membranes, a simpler procedure was applied, where much smaller volumes $(20 \mathrm{~mL})$ were simultaneously ultrafiltrated. Results of this physical fractionation analysis are given in Table 3. Sums of contributions of all physical fractions distinguished with this fractionation procedure were found to change from 89.2 to $111.4 \%$ of the total content of Mn determined in coffee infusions, pointing out the fair reliability of results and this partitioning procedure.

As can be seen, the predominant physical fraction of $\mathrm{Mn}$ are species associated with ligands of the lowest molecular weight, i.e., $<5 \mathrm{kDa}$. The contribution of this fraction was established to be within $61-68 \%$ with the average of $64.6 \%$ and the $\mathrm{CV}$ of $4.8 \%$. The $5-10 \mathrm{kDa}$ fraction, likely to be associated with the presence of high-molecular weight melanoidins (final Maillard reaction products), polysaccharides (galactomannans, arabinogalactants), and proteins in coffee brews (Wang et al. 2011; Bekedam et al. 2006, 2008; Nunes and Coimbra 2001), was also highly abundant, i.e., from 8 to $38 \%$, except for coffee TF. Differences in contributions of 5-10 and 10-30 kDa fractions were presumed to be related to differences in the production of analyzed ground coffees, primarily roasting processes

Table 3 Contributions of physical fractions of Mn species distinguished in coffee infusions using the ultrafiltration procedure

\begin{tabular}{|c|c|c|c|c|c|}
\hline Fraction & $\mathrm{TF}$ & $\mathrm{TE}$ & JA & JK & JCG \\
\hline$>100 \mathrm{kDa}$ & $-^{\mathrm{a}}$ & $-^{\mathrm{a}}$ & $-^{\mathrm{a}}$ & $-^{\mathrm{a}}$ & $-^{\mathrm{a}}$ \\
\hline $50-100 \mathrm{kDa}$ & $-{ }^{\mathrm{b}}$ & $1.3 \pm 0.1$ & $2.1 \pm 0.1$ & $2.3 \pm 0.1$ & $1.1 \pm 0.1$ \\
\hline $30-50 \mathrm{kDa}$ & $3.9 \pm 0.9$ & $1.8 \pm 0.1$ & $2.6 \pm 0.1$ & $11.2 \pm 0.6$ & $7.6 \pm 0.6$ \\
\hline $10-30 \mathrm{kDa}$ & $19.8 \pm 7.3$ & $-^{\mathrm{c}}$ & $9.3 \pm 0.5$ & $2.1 \pm 0.2$ & $3.0 \pm 0.2$ \\
\hline $5-10 \mathrm{kDa}$ & $1.3 \pm 0.3$ & $28.6 \pm 3.0$ & $7.8 \pm 0.9$ & $22.2 \pm 1.5$ & $37.5 \pm 3.2$ \\
\hline$<5 \mathrm{kDa}$ & $64.2 \pm 9.6$ & $67.3 \pm 10.4$ & $68.2 \pm 10.6$ & $61.0 \pm 3.5$ & $62.2 \pm 1.4$ \\
\hline Sum of fractions & $89.2 \pm 12.1$ & $99.0 \pm 10.8$ & $90.0 \pm 10.6$ & $98.8 \pm 3.9$ & $111.4 \pm 3.6$ \\
\hline
\end{tabular}

Average values $(n=2) \pm \mathrm{SDs}$

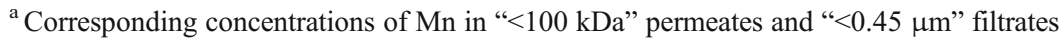

${ }^{\mathrm{b}}$ Corresponding concentrations of $\mathrm{Mn}$ in " $<100 \mathrm{kDa}$ " and " $<50 \mathrm{kDa}$ " permeates

${ }^{\mathrm{c}}$ Corresponding concentrations of $\mathrm{Mn}$ in " $<30 \mathrm{kDa}$ " and " $<10 \mathrm{kDa}$ " permeates 
used and the size of resulting compounds, i.e., high-molecular weight products of the carbohydrate carmelization and the Maillard reaction (Wang et al. 2011). Contributions of other moderate and high molecular weight fractions of $\mathrm{Mn}$, i.e., 30-50 and 50-100 kDa, were rather low. All these results correspond to those achieved in the chemical fractionation analysis and confirm that the smallest cationic species, being simple ions, stable cationic complexes with organic acids, and products of the Maillard reaction and labile species, are prevalent species of $\mathrm{Mn}$ in coffee infusions. These species of Mn can be bioaccessible in $61-68 \%$ from coffee infusions in reference to its total content. It should be mentioned, however, that Mn could undergo many changes during gastric and intestinal digestions due to a change in the $\mathrm{pH}$. This can result both in the formation of new complexes of this metal and/or a partial release of simple ions. For that reason, it is quite essential to conduct a cooperative analysis of coffee infusions with the simulation of gastric and intestinal digestions.

\section{Conclusions}

A simplified method of the analysis of coffee infusions by FAAS was proposed for the determination of total concentration of Mn. In this method, coffee infusions were only previously acidified with $\mathrm{HNO}_{3}$ and directly aspirated prior to measurements versus simple standards solutions. This certainly helped to avoid the contamination of samples and the loss of the analyte and, moreover, it saved the time of the analysis. The fractionation analysis by solid phase extraction and ultrafiltration-based procedures enabled to receive far more important information about possible species of $\mathrm{Mn}$ in coffee infusions than total concentrations. It seems that $\mathrm{Mn}$ is mostly present in the form of cationic species that can be highly bioaccessible for the digestion because of the size of these species, i.e., $<5$ and 5-10 kDa.

Acknowledgments The work was financed by a statutory activity subsidy from the Polish Ministry of Science and Higher Education for the Faculty of Chemistry Wroclaw University of Technology.

Conflict of Interest Pawel Pohl declares that he has no conflict of interest. Ewelina Stelmach declares that he has no conflict of interest. Anna Szymczycha-Madeja declares that she has no conflict of interest. This article does not contain any studies with human or animal subjects.

Open Access This article is distributed under the terms of the Creative Commons Attribution License which permits any use, distribution, and reproduction in any medium, provided the original author(s) and the source are credited.

\section{References}

Abollino O, Aceto M, Bruzzoniti MC, Sarzanini C (1998) Anal Chim Acta 375:299

Anderson KA, Smith BW (2002) J Agric Food Chem 50:2068

Ashu R, Chandravanshi BS (2011) Bull Chem Soc Ethiop 25:11

Bekedam EK, Schols HA, Van Boekel MAJA, Smit G (2006) J Agric Food Chem 54:7658

Bekedam EK, Loots MJ, Schols HA, Van Boekel MAJA, Smit G (2008) J Agric Food Chem 56:7138

Bertrand B, Villarreal D, Laffargue A, Posada H, Lashermes P, Dussert S (2008) J Agric Food Chem 56:2273

Cairns WRL, Hill SJ, Ebdon L (1996) Microchem J 54:88

Dos Santos EJ, de Oliveira E (2001) J Food Comp Anal 14:523

Dos Santos JS, dos Santos MLP, Conti MM (2010) J Braz Chem Soc $21: 1468$

Erdemoglu SB, Pyrzynska K, Gucer S (2000) Anal Chim Acta 411:81 Esquivel P, Jimenez VM (2012) Food Res Int 46:488

Fernandes AP, Santos MC, Lemos SG, Ferreira MMC, Nogueira ARA, Nobrega JA (2005) Spectrochim Acta Part B 60:717

Filho VRA, Polito WL, Neto JAG (2007) J Braz Chem Soc 18:47

Gonzalvez A, Cervera ML, Armenta S, de la Guardia M (2009) Anal Chim Acta 636:129

Grembecka M, Malinowska E, Szefer P (2007) Sci Total Environ 383:59

Hecimovic I, Belscak-Cvitanovic A, Horzic D, Komes D (2011) Food Chem 129:991

Jaganyi D, Madlala PS (2000) J Sci Food Agric 80:1

Jaganyi D, Vanmare J, Clark T (1999) J Sci Food Agric 79:323

Karadjova I, Izgi B, Gucer S (2002) Spectrochim Acta Part B 57:581

Liu Y, Kitts DD (2011) Food Res Int 44:2418

Martin MJ, Pablos F, Gonzalez AG (1996) Anal Chim Acta 320:191

Martin MJ, Pablos F, Gonzalez AG (1999) Food Chem 66:365

Matsuura H, Hokura A, Katsuki F, Itoh A, Haraguchi H (2001) Anal Sci 17:391

McKinnon AJ, Scollary GR (1997) Talanta 44:1649

Nunes FM, Coimbra MA (2001) J Agric Food Chem 49:1773

Odegard K, Lund W (1997) J Anal At Spectrom 12:403

Oleszczuk N, Castro JT, da Silva MM, Korn MGA, Welz B, Vale MGR (2007) Talanta 73:862

Onianwa PC, Adetola IG, Iwegbue CMA, Ojo MF, Tella OO (1999) Food Chem 66:275

Ozdemir Y, Gucer S (1998) Food Chem 61:313

Pohl P (2007) Microchim Acta 159:325

Pohl P, Prusisz B (2007) Talanta 71:715

Pohl P, Stelmach E, Welna M, Szymczycha-Madeja A (2013) Food Anal Methods 6:598

Powell JJ, Burden TJ, Thompson RPH (1998) Analyst 123:1721

Rodrigues CI, Marta L, Maia R, Miranda M, Ribeirinho M, Maguas C (2007) J Food Comp Anal 20:440

Santos EE, Lauria DC, da Silveira CL P (2004) Sci Total Environ 327:69

Schumann K, Elsenhans B (2002) J Trace Elem Med Biol 16:139

Suseela B, Bhalke S, Vinod Kumar A, Tripathi RM, Sastry VN (2001) Food Addit Contam 18:115

Svendsen R, Lund W (2000) Analyst 125:1933

Templeton DM, Ariese F, Cornelis R, Danielson LG, Muntao H, Van Leeuwen HP, Lobisnki R (2000) Pure Appl Chem 72:1453

Wang HY, Qian H, Yao WR (2011) Food Chem 128:573

Watzke HJ (1998) Trends Food Sci Technol 9:320 